\title{
Multimedia Production and Multi(media) Literacy in
}

\section{Gymnasiums}

\author{
Srečo Zakrajšek
}

IAM, College for Multimedia, Ljubljana, Leskoškova 12. Ljubljana1000, Slovenija

\begin{abstract}
The article displays the possibilities for introducing multimedia production based on computer science to gymnasiums (general secondary school programs), where students who usually continue their education at college are educated. The purpose of the research was to prepare an assessment of the situation and recommendations to gymnasiums on how to improve the situation in this field and what options and opportunities appear for schools and the media environment in which they are active. Special attention was paid to the situation of activities (extracurricular activities and optional subjects) related to multimedia production and uses of ICT (information-communication technology).
\end{abstract}

Key words: Multimedia, multi(media) literacy, gymnasium.

\section{Introduction}

The article presents the possibilities and opportunities offered by modern multimedia production in gymnasiums (general secondary school) and how they can be sensibly included in the learning process in all organizational forms of such schools. Our research work and conclusions are very important for schools policy and will be encourage principals and teachers to develop the activity in schools and consequently improve multimedia literacy in different activities which allow and supported the contemporary, interesting, motivational and efficient education process. Directing the work of youths towards multimedia production in gymnasiums could help to involve and improve computer, technical and practical engineer education on the field of modern IC technologies and focus more students for technical studies and computer science.

At the core of gymnasiums lie general subjects with optional subjects, extracurricular activities and project

Corresponding author: Srečo Zakrajšek, professor, research fields: multimedia production and multimedia literacy in secondary and higher schools system. E-mail: sreco.zakrajsek@iam.si. work are available and a part of multimedia activities occur in connection with the functional activities of the school. The problems and requirements which are met with in such introduction and implementation are also presented. Slovenia has plenty of experience in this field as we were among the most advanced EU countries during the implementation of modern technologies, and we have also highly developed extracurricular subjects and other activities which include creative preparation and use of content and events with the related elements of multimedia production and literacy.

Knowledge, skills and competences in multimedia are extremely important for the youth for successful work at school and in society [1] and for their decisions on further studies and professional orientation for many of them. The importance of knowledge and the use of modern media technology can be found in Ref. [2]. Successful work in modern professions is based on different types of literacy, and multimedia literacy is at the very top as it connects and upgrades other literacy. Based on the recommendations [3] for media literacy, multimedia literacy upgrades it in skills (preparation of simple 
synopses and screenplays, basics of photography, recording, editing of simple AV products), critical evaluation of $\mathrm{AV}$ products and communication capability (basics of public speaking, use of interactive multimedia applications).

Literacy in multimedia is characteristic to those who know the specifics of acquiring, preparation, analysis and assessment of multimedia literature, and who actively use multimedia applications. Literacy in multimedia combines all types of literacy-e-literacy, digital, computer, ICT, technical and media literacy. It is also the most demanding, yet at the same time most contemporary, useful and efficient.

Modern multimedia production which is based on digital technologies and two or more media elements, along with its products, can be found and used in gymnasiums in a more or less organized manner every day: preparation and use of the web, presentation literature such as overlays, AV products, animations, demonstrations and simulations of various experiments, information and electronic boards, animated displays of various content, educational platform with web classrooms, digital literature, web portals and networks, smart house, etc.. With proper knowledge, organization, cadres and resources each school can obtain a modern system of multi(media) literacy and quality multimedia production.

Hobbs $[4,5]$ has performed many researches in multimedia production among the youth, from aspects of production and use. Through these researches he finds that youths daily use information, create it, play with it and manipulate it in various media, therefore, it is extremely important that they are appropriately educated and made aware of it.

With sensible and applicative use of modern technology, the attitude of youths to science and technology is also changing. There is a democratization of techno-science, and the field of product and services usability is moving away from technological determinism. Brewin [6] places digital technology into a wider context.
Many researchers are active in the field of connecting the educational process with modern technology. Singhal and Rogers [7] think that education should be more active and that it should provide quality educational multimedia products. In gymnasiums, this can be achieved with modern technological support and by upgrading various activities which are already present, as well as with new approaches as they provide the youth who go to college or begin working equal entry to a very competitive world which demands innovative work and the search for new solutions and products.

Tulodziecki and Grafe [8] present media in the context of media literacy in the German education system. They deal with the problem of including the extremely fast development and expansion of media into the education system. "Furthermore, we think that national efforts should lead more often to international and interdisciplinary collaborations and partnerships in research and practice to globally promote developments of learning with media and media literacy education. To understand the national context in different countries is a necessary prerequisite to find links for partnerships and joint efforts."

Modern media is based on art, design (graphics design, the web) and on communication (marketing, journalism, media). Products must be designed in such a way that they are most appropriate for use; they must enable high productivity and customer satisfaction, and cause as few problems as possible. Modern products must have quality, value and satisfy the customer in the long term.

Introduction of modern technology positively affects multimedia literacy which is defined as "an ability to work across text, image, sound, and moving image with equal fluency" [9].

Multimedia production of youth has several particularities and characteristics as it is based on the opinions and experiences of youth which can cause problems if they must adhere to the classical rules of multimedia production [10]. It is important in 
multimedia production to provide an analysis and a professional evaluation of products and then influence the youth to improve their work with interviews, brainstorming, and similar [11].

The article describes importance of radio shows for presentation of youth activities and also the connection between the language in schools and in shows. The importance of media production of youth for all types of literacy, especially multimedia literacy, is also described. Youth radio shows encourage teachers to emphasize reading, speaking and dialogue in the curriculum. A research was performed in creative shows which occurred in studios outside schools.

The youth spends a lot of their time outside school with modern technologies. Mostly, social networks are involved; vlogging or video blogging is also popular [12], being a participatory activity accessible to almost everyone [13]. Numerous researches and opinions exist on the importance and influence of modern technologies, which can be also found in Ref. [14]. Some of the above possibilities have already been included in educational process as they have proven to be very efficient.

\section{Materials and Methods}

Based on all the research and facts in multimedia production, we have performed a research in Slovene gymnasiums.

In October and November 2013, we have performed a research in Slovene gymnasiums on multimedia production in gymnasiums [15], which included an activity analysis with review of curricula, websites and annual work plans, and we performed a survey among school principals. The purpose of the research was to determine the situation of multimedia production in Slovene gymnasiums, what the school management's vision is and what the future needs in this field are. We have paid special attention to the situation of activities (extracurricular activities and optional subjects) related to multimedia production.
The purpose of the research was to prepare an assessment of the situation and recommendations to gymnasiums on how to improve the situation in this field and what options and opportunities appear for schools and the media environment in which they are active. We have discovered through previous research that the interest among youths for such activities is great, and that schools mostly offer few possibilities, and definitely fewer than students have in Slovene elementary schools.

Until 2008, Slovenia was among the leading countries in the EU in ICT, but the situation has worsened with the recession. All this had negative consequences for the equipping of schools and particularly for the diminished use of modern technologies in classes, as well as the use of multimedia production in schools. According to data from 2012, Slovenia is slightly above the EU 25 average in computer equipment, but has 2 to 3 times fewer computers per student compared to developed countries; more favorable information is that regarding other equipment (interactive boards, projectors, laptops, virtual environments) and the internet, Slovenia is at the level of most developed countries.

Fortunately, modern mobile multimedia devices have appeared in this period, other equipment became less expensive, so most students have their own devices to access various contents and also do numerous other activities. On average, $46 \%$ of $\mathrm{EU}$ students use a telephone and $16 \%$ a laptop for learning [16], and over $95 \%$ of students in Slovenia have mobile phones.

As classical computer classrooms are making way for mobile devices which students have in classrooms, there is a need for special premises and more demanding, special equipment which enables multimedia production. It is reasonable to organize multimedia centers in gymnasiums which connect the context, events, production, distribution and archive segments of the system. 
Since gymnasiums have already skipped one technological phase without major damage (the equipment of classrooms with stationary computers), we have the opportunity to quickly catch up with the new situation and concepts where the equipment is not so important and creative and innovative people and numerous networks are becoming more important; one of them is the MOOCs (massive open online courses) concept. A congress was held on this issue [17].

Our Research included 39 independent Slovene gymnasiums. We analyzed their activities (by analyzing websites and annual work plans). In a broader sense, we reviewed all activities of these schools and the possibilities for the use of modern technology and equipment (for monitoring, analyzing, archiving, displaying, promotion, etc. of activities), and in the narrow sense those which affect the multimedia production capabilities of the individual school the most. The survey was sent to all principals and acquired responses from $25.6 \%$ of the surveyed schools.

After the analysis of the work of gymnasiums and the completed surveys, we assessed that the survey was completed mostly by principals who have already set the foundation for multimedia production, and the others have only started to acquire basic information with teachers performing individual elements of multimedia production, but it has not been established on the school level yet. In the survey result analysis we mostly assessed only the opinions of principals in gymnasiums that already have reasonably well-developed multimedia production (there are about 6,000 students combined in these schools) or a positive attitude towards it; by using analysis of websites and other documents, we assessed all schools.

\section{Results and Discussion}

Survey results showed that principals think that $50 \%$ of youths are highly motivated to produce various multimedia products and $40 \%$ agree that multimedia production positively affects students' creativity.

First let us mention the activities which create or use multimedia products and are present at most gymnasiums:

- All gymnasiums have websites;

- Almost every gymnasium has internet classrooms;

- All gymnasiums organize celebrations, presentations, exhibitions and sporting events, organize various camps and exchanges which represent the foundation for multimedia production [15];

- Many gymnasiums have organized research activities where multimedia production is extensively used;

- Most gymnasiums have projects which mostly connect through the internet.

Other activities which are not present in all gymnasiums were divided into two groups. The first group includes activities which directly enable and support the implementation of multimedia production; the second one includes those which use multimedia products or provide contents and events for it. Both require and encourage multi(media) literacy.

Group 1: Activities which directly enable and support multimedia production in Slovene gymnasiums: architecture, architecture sketching, BYOI (bring your own ideas), newspaper (classical and web), debate club, film school, photography, comics creation, sculpturing and drawing, art, literature, puppetry, journalism, discussion club, computers, screenplay workshop, school radio and television station, video and film, creative writing.

Group 2: Activities in Slovene gymnasiums which use multimedia products or provide content and events for it: active citizenship, aquaristics, English drama, botany, Cisco, girl choir, drama group, ECO school, economy, philosophy, French drama, geography, music, theatre group, histologic techniques, improvisational group, languages, mathematics, 
microbiology, mycology with lichens, my company, natural science (astronomy, biology, physics, geology, chemistry, chemistry afternoons), OpenLab, concert organization, choirs (female, mixed), entrepreneurship, law, FCE project preparation (various), volunteer social work, first aid, research work, dance orchestra, SIMBIOZA (symbiosis), sociology, sports activities (competitive sports, cheerleading, dancing, aerobics, recreational sports), camps and outdoor schools, talent show, UNICEF, instrument learning, healthy schools, history, etc..

We have determined that there are great differences between gymnasiums (the results are shown in Table 1). Some gymnasiums have practically no activities from the wider or the narrower list, and several schools have over 30 activities, some even over 40 . Eighteen gymnasiums do not offer even one of the activities (in the narrower sense) required for multimedia production. Not one school has all the basic activities necessary for multimedia production (photo, video, journalism, art, school newspaper, school radio, school TV). Three or more activities (as a chosen minimum to label the school as having multimedia production) are performed at 10 gymnasiums or $25.6 \%$ of all gymnasiums.

We have also monitored three sets of activities (the results are shown in Table 2) which significantly affect events (which can be an important object of multimedia production): sports events (present at almost every gymnasium), choirs and music groups with theatre groups. $51 \%$ of gymnasiums have at least one of these activities.

Gymnasiums have great potential and interest of students for multimedia production and also a series of obstacles which prevent it. A positive fact is that first, the determination of school management is necessary for a change, as other prerequisites, such as equipment (the results are shown in Table 3 ), mentors, product publishing etc. present a minor problem.

Modern gymnasiums must implement part of their activities in form of projects, international if possible, which are also running online; meetings and conferences are done remotely, foreign language is used and communication is practiced, project work is made familiar, etc.. Ref. [18] presents the KOD (knowledge-operators-and-domains) model, used by the Indiana University School of Informatics HCI Graduate Program where students prepare various real projects throughout the life cycle and learn of various work methods in the process (lectures, presentations, discussions, assessment, verification of usability, etc.). Projects can be group or individual, related in a way that the results can be upgraded and used in other projects as well.

Table1 Basic activity, which directly enable and support multimedia production in Slovene gymnasiums.

\begin{tabular}{lll}
\hline Activity & Number of gymnasium with this activity & $\%$ of gymnasium with this activity \\
\hline Photography & 8 & $21 \%$ \\
Video, film & 7 & $18 \%$ \\
Journalism & 5 & $13 \%$ \\
Drawing, art, sculpture & 11 & $28 \%$ \\
School newspaper & 7 & $18 \%$ \\
School radio & 5 & $13 \%$ \\
School TV & 1 & $3 \%$ \\
\hline
\end{tabular}

Table 2 Activities which significantly affect on multimedia production in Slovene gymnasiums.

\begin{tabular}{lll}
\hline Activity & Number of gymnasium with this activity & \% of gymnasium with this activity \\
\hline Sports events & 39 & $100 \%$ \\
Theatre groups & 18 & $46 \%$ \\
Choirs and music groups & 17 & $44 \%$ \\
\hline
\end{tabular}


Table 3 Answer on the question for school management: What are the current options for a modern, technologically assisted multimedia productions in your school?

\begin{tabular}{ll}
\hline Value & $\%$ \\
\hline excellent & 10 \\
very good & 30 \\
good & 50 \\
satisfactory & 10 \\
Poor & 0 \\
\hline
\end{tabular}

Gymnasium must familiarize their students with the application for tenders and the preparation of applications and reports since many of them will later work in such a way. There are many possibilities with numerous home and foreign tenders and competitions.

The setting up and implementation of multimedia production in gymnasium is a project where first the decision has to be made that, alongside activities which lead students to a successful matura (baccalaureate) exam, appropriate activities which can satisfy various interests of youth and enable the development of their talent in several fields are organized. Until the country sets up a system that requires knowledge and skills in modern technology within the external examination at the matura exam, such activities will be organized only within optional subjects and activities. This may be better from the perspective of the creativeness and non-regulation of the field, but it is too dependent on preparation of individual gymnasium management.

Besides the preparation of appropriate programs, the education and qualification of teachers is most important as they become modern teachers and mentors. Teachers usually require additional education and training for multimedia production as regular education usually does not cover it.

Greater selection can come only if the obligatory gymnasium program is reduced and there are more available positions with less hours for external experts since principals also assess that they are not convinced of any great interest of most teachers to cooperate. Only $40 \%$ think that teachers are quite interested in such work.

Research shows that qualified, motivated and confident teachers are more important than technology, and creativity is becoming more important. A detailed presentation of their vision of a modern teacher is also presented by Microsoft (response).

All principals do agree that it would be very helpful if the school had a multimedia production expert among their employees. This is supported by EU guidelines.

This is also confirmed by the results of our research (Table 4).

Our research shows that principals do not know the possibilities or are not convinced by the possibilities of new technologies and products for the school in acquiring funds (sponsorships, tenders, local community, etc.) - only $30 \%$ believe in a positive outcome in this field.

Schools will have to consider EU policy and the related national policy in the following years. These documents set several demands as well as challenges for schools, and offer numerous possibilities. The most important are the Commission Recommendation on media literacy in the digital environment [19], Horizon 2020 [20] or Media and Information Literacy of UNESCO. In 2013, the European Commission presented the Open Europa 2013 action plan [21] to increase innovations and digital skills in schools. There will be opportunities for innovation in schools within this program, especially for the spreading use of freely accessible sources for improving the information-communication technology (ICT) structure. We have determined in the research that $30 \%$ of schools who have returned a completed survey are not familiar with this program, and that this percentage is definitely even bigger for all schools.

Gymnasiums want to introduce multimedia production and increase multi(media) literacy, and they need professional help and financing to employ a qualified expert as well as a co-financing for the education and qualification of teachers. 
Table 4 Answers on the argument: It would help if the operation of the multimedia center may employ a technical assistant.

\begin{tabular}{ll}
\hline Value & $\%$ \\
\hline I strongly agree & 60 \\
I agree & 40 \\
I do not knowwhat to say & 0 \\
I disagree & 0 \\
\hline
\end{tabular}

\section{Conclusion}

Research showed that none of the gymnasiums in Slovenia have a fully organized multimedia production, and only $25 \%$ have a solid multimedia production. Half of the gymnasiums are not active in this field. Principals think that students have solid media literacy, whereas they are just starting with multimedia literacy. There is hope that the results of and suggestions from the research will encourage principals to develop the activity in schools and consequently improve multimedia literacy. The biggest influence on the introduction of modern technologies to gymnasiums would be achieved if knowledge, skills and competences from this field were a prerequisite for successfully passing the matura exam. At the moment, the larger portion of multimedia literacy is provided by opportunities and demands outside school.

When reviewing activities in Slovene gymnasiums throughout the year, such as activities, optional subjects or other forms, we have determined that there are great differences among gymnasiums and that they offer different activities in different numbers. A very important finding is that some activities encourage others as a practical need for cooperation will occur, and desires and demands of students and parents, teachers-mentors and external mentors will occur at the same time. The range and implementation of these activities mostly depend on school management and are largely related with the work quality at the school.

The organization of various activities and multimedia production presents many opportunities for acquiring additional knowledge, skills and competences for mentors or external mentors and it also enables a future study and professional orientation, satisfies special desires and talents; finally it also requires the presentation and reviewing of results in a real environment, along with promotion and acquiring references. As a rule, most activities enable work presentations at events, in media, social networks, etc.

Since education in gymnasiums is mostly based on general subjects and theoretical teaching, most youths decide to study similar study courses which represents a certain problem as technical and practical engineer educated and qualified cadres are scarce, also in the development and use of modern technologies.

Directing the work of youths towards multimedia production in gymnasiums could partly help to improve the situation, while having many additional direct and indirect effects. These appear in the contemporary, interesting, motivational and efficient education process and multimedia products which are useful for the work and promotion of the school. The intertwining of the school with the environment is improved, the recognition and competitiveness of school is increased, along with the interest of students for acquiring education at a specific school.

The results of the survey and international comparisons show that Slovene gymnasiums have realistic possibilities for quality multimedia production if they make a conscious decision to implement it and acquire appropriate professional and financial support.

\section{References}

[1] Meyers, EM. 2013. "Digital Literacy and Informational Learning Environments: An Introduction. Learning, Media and Technology." http://www.tandfonline.com/doi/abs/10.1080/17439884.2 013.783597.

[2] Powers, E. 2010. "Teaching news literacy in the age of new media: Why Secondary School Students Should Be Taught to Judge the Credibility of the News They Consume." Washington University in St. Louis, http://openscholarship.wustl.edu/cgi/viewcontent.cgi?arti cle $=1454 \&$ context $=$ etd

[3] EAVI, 2011. Testing and Refining Criteria to Assess 
Media Literacy Levels in Europe. Final Report.

[4] Hobbs, R. 2006. "Reconceptualizing Media Literacy for the Digital Age." In Digital Literacies for Learning, edited by Martin, A., and Madigan, D. London: Facet, 99-109.

[5] Hobbs R .2007. "Approaches to Instruction and Teacher Education in Media Literacy”. Accessed June 15, 2014. http://unesdoc.unesco.org/images/0016/001611/161133e. pdf.

[6] Brewin, M. 2014. "Media, Society, World, Social Theory and Digital Media Practice." New Media \& Society 15 (7): 1195-97.

[7] Singhal, S., and Rogers, EM. 2002. "A Theoretical Agenda for Entertainment-Education." Communication Theory 12 (2): 117-35.

[8] Tulodziecki, G. and Grafe, S. 2012. "Approaches to Learning with Media and Media Literacy Education Trends and Current Situation in Germany." Journal of Media Literacy Education 4 (1): 44-60.

[9] Sefton-Green, J. 2000. Young People, Creativity, and New Technologies. London: Routledge.

[10] Fleetwood, N. N. 2005. "Authenticating Practices: Producing Realness, Performing Youth." In Youthscapes: The Popular, The National, The Global, edited by Maira, S., and Soep, E. Philadelphia: University of Pennsylvania Press, 155-72.

[11] Soep, E. 2006. "Beyond Literacy and Voice in Youth Media Production.” Revues des Sciences de L Education de MCGILL 41 (3): 197-213.

[12] Snelson, C. 2013. "Vlogging about School on YouTube: An Exploratory Study." New Media \& Society 26: 1-19.

[13] Jenkins, H., Clinton, K., Purushotma, R., Robison, A. J., and Weigel, M. 2006. Confronting the Challenges of Participatory Culture: Media Education for the 21st
Century. Digital Media and Learning. The MacArthur Foundation, Illinois, USA. http:/www.macfound.org/press/publications/white-paper -confronting-the-challenges-of-participatory-culture-medi a-education-for-the-21st-century-by-henry-jenkins/.

[14] Chouliaraki, L. 2008. "The Media as Moral Education: Mediation and Action." Media, Culture \& Society 30 (6): 831-52.

[15] Research. 2013. "Multimedijskaprodukcija v slovenskihgimnazijah (Multimedia production in Slovenian gymnasiums.” IAM, Ljubljana.

[16] Survey of schools. 2013. "ICT in Education, Benchmarking Access use nad Attitudes to Technology in Europes Schools" Accessed June 15, 2014. https://ec.europa.eu/digital-agenda/node/51275.

[17] 1 st. Internet od Education Conference - "The role of Computer Science in the Internet of Education" Accessed June 15, 2014. http://videolectures.net/internetofeducation2013_ljubljan a/.

[18] Faiola, A., Davis, SB., and Edwards, RL. 2010. "Extending Knowledge Domains for New Media Education: Integrating Interaction Design Theory and Methods." New Media \& Society 12 (5): 691-709.

[19] "Commission Recommendation on media literacy in the digital environment for a more competitive audiovisual and content industry and an inclusive knowledge society." (2009). Brussels, Belgium: European Commission.Accessed June 15, 2014. http://eur-lex.europa.eu/LexUriServ/LexUriServ.do?uri= CELEX:32009H0625:EN:NOT.

[20] Horizon 2020. 2014. Accessed June 15, 2014. http://ec.europa.eu/research/horizon2020/index_en.cfm

[21] Open Education Europa. 2013.Accessed June 15, 2014. http://www.openeducationeuropa.eu/. 